\title{
Immunopathology of the duodenal mucosa of HIV-positive patients during combined antiretroviral therapy
}

\section{F.R. Machado ${ }^{1}$, \\ C. Pagliari' ${ }^{3}$, H. Caiafa ${ }^{2}$, \\ R. Tapajós ${ }^{1}$ and \\ M.I.S. Duarte ${ }^{2}$}

\author{
1Divisão de Doenças Infecciosas e Parasitárias, \\ ${ }^{2}$ Divisão de Laboratório Central, \\ ${ }^{3}$ Departamento de Patologia, Hospital das Clínicas, \\ Universidade de São Paulo, São Paulo, SP, Brasil
}

\begin{abstract}
Correspondence
F.R. Machado

Divisão de Clínica de Moléstias Infecciosas IC, HC, FM, USP

Av. Enéas C. Aguiar, 255, 4o andar 05403-000 São Paulo, SP Brasil

Fax: +55-11-3085-1755

E-mail: genauhaus@uol.com.br

Research supported by FAPESP. $\ldots \ldots \ldots \ldots \ldots \ldots$
\end{abstract}

Received February 17, 2005 Accepted October 25, 2005

\begin{abstract}
The objective of the present study was to evaluate the duodenal mucosa of HIV-infected patients during antiretroviral therapy. This was an observational study conducted on HIV-positive patients and a control group. Group 1 comprised 22 HIV-negative individuals while 38 HIV-positive individuals were classified according to the $\mathrm{CDC}$ 1993 classification into group 2 (A1 or A2) or group 3 (B2, A3, B3, $\mathrm{C} 2, \mathrm{C} 3$ ). All subjects were submitted to upper gastrointestinal endoscopy with duodenal biopsies. Qualitative, semi-quantitative and quantitative histological analyses were performed. Results were considered significant when $\mathrm{P}<0.05$. A higher prevalence of inflammatory infiltrate and eosinophilia was observed in the HIV group, together with a reduction in mucosal CD4+ lymphocyte (L) counts [median (lower-upper quartiles), 12.82 (8.30-20.33), 6.36 (1.75-11.66) and 1.75 (0.87-3.14) in groups 1, 2 and 3, respectively] which was not correlated with disease stage. The extent of $\mathrm{CD} 4+\mathrm{L}$ count reduction was similar in blood and duodenal mucosa. Normal CD8+L and $\mathrm{CD} 45 \mathrm{RO}+\mathrm{L}$ counts, and normal numbers of macrophages and antigen-presenting cells were also found in the HIV patients. The cytokine pattern did not differ among groups. Tissue HIV, assessed by p24 antigen, correlated with a higher $\mathrm{CD} 45 \mathrm{RO}+\mathrm{L}$ count $(77.0$ (61-79.8) and 43.6 (31.7-62.8) in p24+ and p24-, respectively, $\mathrm{P}=0.003)$, and IL-4 positivity (100 and $48.2 \%$ in p24+ and p24-, respectively, P = 0.005). The duodenal mucosa of HIV+ patients showed a relatively preserved histological architecture. This finding may be characteristic of a population without opportunistic infections and treated with potent antiretroviral therapy, with a better preservation of the immune status.
\end{abstract}

\section{Introduction}

Histologic findings of the intestinal mucosa in advanced stages of HIV infection have been well described. They vary from mild inflammatory infiltrates (1-3) to vari-

\section{Key words}

- Intestinal histopathology

- Cytokines

- Human immunodeficiency virus

- Acquired immunodeficiency syndrome

- Antiretroviral therapy

- CD4+ $\ldots \ldots \ldots \ldots \ldots \ldots$ 
the intestinal mucosa as an HIV reservoir, which sustains HIV replication during clinical latency or even during highly active antiretroviral therapy (HAART) $(8,9)$. The high numbers of mucosal CD4+ $\mathrm{T}$ lymphocytes (CD4TL) and their activation status contribute to a high replication rate in the mucosa. A reduction of these cells during the progression of the disease has been demonstrated (10), even in the early phases of infection (11-13). Changes in cell populations are not clearly associated with alterations in the mucosal architecture, but cytokines may play a role in these interactions $(8,14)$. Different and even conflicting cytokine patterns have been demonstrated in the mucosa $(13,15-19)$. The intestinal mucosa has not been well studied in the early stages of the infection because it is difficult to submit asymptomatic individuals to invasive procedures. In previous studies of the early phase, many patients had low peripheral CD4TL counts or symptoms related to immunosuppression, which precluded their classification into the early stages of the infection (11-13).

In most studies, the subjects were either off antiretroviral therapy or using only monotherapy with nucleoside reverse transcriptase inhibitors (NRTI). The effects of HAART on the mucosa are yet to be defined (20). It has been shown that the use of HAART leads to a decrease in the prevalence of intestinal opportunistic infections (21) and in the severity of symptoms (22), as well as an increase in the number of mucosal CD4TL after resolution of cryptosporidiosis (23). In the present study, the mucosal architecture, the different cell populations and the cytokine pattern of the duodenal mucosa were evaluated in HIV-positive (HIV+) patients in different phases of the infection. All subjects were using at least two NRTI. The histologic findings were correlated with disease stage and degree of immunosuppression as assessed by viral load and peripheral CD4TL counts.

\section{Patients and Methods}

\section{Patients}

A control group (group 1) was recruited from the Service of Digestive Endoscopy, Hospital das Clínicas, Universidade de São Paulo, São Paulo, SP, Brazil. They were selected on the basis of the following criteria: age above 18 years, previously health individuals submitted to upper digestive endoscopy only because of dyspepsia, and normal macroscopic exams. These individuals were taking no medications and all were submitted to a serological test to assure their HIV-negative status. The HIV+ patients were recruited among the outpatients of the Division of Infectious Diseases, Hospital das Clínicas, Universidade de São Paulo, and classified into two groups according to the 1993 CDC Revised Classification System (24). Group 2 consisted of asymptomatic patients from category A1 or A 2 and group 3 comprised patients with advanced disease from categories B2, A3, B3, C1, C2, C3. All patients were recruited from March 1999 to March 2000. The protocol was approved by the Hospital Ethics Committee and each individual gave written informed consent.

The following exclusion criteria were considered for the HIV groups: age under 18 years, chronic diarrhea in the previous 12 months defined as 3 or more episodes per day, neoplasia, or opportunistic infection of the small intestine. The presence of opportunistic infections was excluded after three parasitologic stool exams including Cryptosporidium and Isospora exams and analysis of the duodenal biopsy.

\section{Clinical assessment}

All HIV+ subjects answered a questionnaire regarding gastrointestinal symptoms and the use of antiretroviral therapy. The information given was checked with the patients' charts. This information was used to 
determine the presence of any exclusion criteria and to assign the patient to one of the study groups. Peripheral CD4+TL, CD8+TL and $\mathrm{CD} 3+\mathrm{TL}$ counts were determined by flow cytometry at the time of endoscopy in all patients, including the control group. Peripheral viral burden, assessed by quantitative PCR (Amplicor, Roche Diagnostic Systems, Inc., Branchburg, NJ, USA), was determined in all $\mathrm{HIV}+$ patients. The results are presented on a $\log 10$ scale. In those with an undetectable viral burden, a value of 200copies $/ \mathrm{mL}$ was used for statistical analysis because this was the lower limit of detection.

\section{Intestinal absorption and nutritional status}

All HIV+ patients were submitted to a Dxylose (Sigma, St. Louis, MO, USA) test to assess the presence of carbohydrate malabsorption. Nutritional status was evaluated on the basis of body weight and determination of serum albumin, magnesium and ferritin. Control patients from group 1 were not submitted to D-xylose tests due to operational problems. In HIV+ patients, the results were interpreted on the basis of reference ranges provided by the manufacturer.

\section{Histopathology}

All subjects underwent upper gastrointestinal endoscopy with biopsy samples taken from the second or third part of the duodenum. The fragments were immediately oriented and two were fixed in formalin and embedded in paraffin for histological examination. Another fragment was embedded in tissue freezing medium (Leica Instruments GmbH, Nussloch, Germany), snap frozen in $99 \%$ isopentane cooled in a liquid nitrogen bath, transported in liquid nitrogen, and stored at $-70^{\circ} \mathrm{C}$. Cryostat sections were placed on slides and stored at $-20^{\circ} \mathrm{C}$ before immunohistochemistry.

Sections were stained with hematoxylin and eosin and also submitted to histochemis- try techniques such as Ziehl-Neelsen, Grocott, Brown-Brenn, and Giemsa staining to exclude the presence of mycobacterial, fungal, bacterial, and Cryptosporidium infection, respectively. The presence of Cytomegalovirus, Adenovirus or Herpes simples virus was determined by immunohistochemistry (25). All specimens were coded, with no identification of the groups and read by a blinded observer who did not know to which group the specimen belonged.

Histological analysis. Histological analysis was performed on hematoxylin and eosin-stained sections. The presence of inflammation was scored semi-quantitatively as 0 (absent), + (mild), ++ (moderate), and +++ (severe). The number of eosinophils was scored as 0 (normal), + (mildly increased), and ++ (moderately/severely increased), and the villus to crypt ratio and the number of mitoses were defined as normal, diminished, or increased.

The villus to crypt ratio and the degree of lamina propria infiltrate were determined qualitatively by visual inspection and compared with normal control values. Formal morphometric analyses were not performed.

Immunohistochemistry. Immunohistochemistry studies were performed on paraffin-embedded tissue using monoclonal antibodies to CD4+, CD8+, CD45RO+L, CD68+, S100+, and CD25+ cells (Dako Corporation, Carpinteria, CA, USA) by the streptavidin-biotin complex technique. The CD4+, CD8+ and CD25+ cells were better visualized by using a signal amplification system (CSA, Dako) (26). The CD45RO receptor was used to determine the total number of $\mathrm{T}$ cells in the mucosa since it is expressed by the majority of TL and the technique for CD3 receptor detection was not available. Cryostat sections were submitted to the same technique in order to determine the presence of cytokines using monoclonal antibodies to IFN- $\gamma$, TNF- $\alpha$, TGF- $\beta$, IL- $1 \alpha$, IL-1 $\beta$, IL-5, IL-7, IL-8 (Genzyme, Cambridge, MA, USA), and IL-4 (R\&D Systems, Minneapo- 
lis, MN, USA).

The cell populations were determined by counting the cells above the muscularis mucosae using a square grid with a set of lines $\left(1 \mathrm{~cm}^{2}\right)$, which was superimposed on the duodenal biopsy at 400X magnification. Lymphoid aggregates or poorly oriented areas were not considered. Five to ten fields were analyzed for each subject and data are reported as mean number of cells $/ \mathrm{cm}^{2}$ in a high power field.

Because of the small number of cells expressing cytokines in most cases, a qualitative analysis was performed. The sample was considered to be positive if there were at least two positive cells. The number of TNF$\alpha-$, IL-1 $\alpha-$-, IL-1ß-, and IFN- $\gamma$-positive cells permitted their semi-quantitative evaluation. Samples were classified as negative (-), mildly positive $(+)$ or moderately/intensely positive (++). TNF- $\alpha$ was the only cytokine that could be measured quantitatively. The results for this cytokine are also reported as number of positive cells per high power field.

The presence of HIV was also assessed by the streptavidin-biotin complex technique using a monoclonal antibody to p24 (Dako, Hamburg, Germany). The sample was considered to be positive if any cell was definitely labeled or if there was the characteristic positive infiltrate among cells.

\section{Statistical analysis}

Qualitative variables were analyzed by

Table 1. Demographic characteristics of the patients studied.

\begin{tabular}{|c|c|c|c|c|}
\hline Characteristic & $\begin{array}{l}\text { Group } 1 \\
(\mathrm{~N}=22)\end{array}$ & $\begin{array}{l}\text { Group } 2 \\
(\mathrm{~N}=14)\end{array}$ & $\begin{array}{l}\text { Group } 3 \\
(\mathrm{~N}=24)\end{array}$ & Global \\
\hline & 42.5 & $.0-40.0)$ & $34.0(30.5-41.0)$ & $35.0(29.5-44.5)$ \\
\hline Male gender & 4 (8.2\%) & 9 (64.3\%)* & $20(83.3 \%)^{\star}$ & $33(55.0 \%)$ \\
\hline
\end{tabular}

Age data are reported as medians (lower-upper quartile). Male gender data are reported as N and percent. Group 1: 22 HIV-negative individuals; group 2: HIV-positive individuals classified as A1 or A2, and group 3: HIV-positive individuals classified as B2, A3, B3, C2, and C3 according to the CDC 1993 classification.

${ }^{\star} \mathrm{P}=0.0001$ compared to group 1 (chi-square test). the Pearson chi-square test with MantelHaenszel correction or by the Fisher exact test. Wald's multiple comparison test was used when necessary. Since the majority of continuous variables did not have normal distributions, non-parametric tests were used. Data are reported as median (lower-upper quartiles) and were submitted to the MannWhitney or Kruskal-Wallis test. Multiple comparisons were made by the Dunn test and the results are reported as confidence intervals. The Spearman correlation test and linear regression were used to analyze quantitative variables. The results were considered to be statistically significant when $\mathrm{P} \leq$ 0.05 .

\section{Results}

\section{Demographics}

Sixty patients were included on the study, distributed as follows: group 1, $22 \mathrm{HIV}$ negative subjects, and two HIV+ groups: 14 patients in group 2 (asymptomatic group) and 24 patients in group 3 (advanced disease group). The demographic characteristics are listed in Table 1. The risk factors in the HIV+ population were as follows: $59.7 \%$ were homosexual or bisexual, $1.8 \%$ were intravenous drug users, and $1.8 \%$ had received blood transfusions. No opportunistic infections were detected in any of the HIV+ patients either in the stool examinations or by the histopathological analysis.

\section{Clinical assessment}

The peripheral CD4+TL, CD8+TL, and CD3+TL counts and viral loads are given in Table 2. Viral load was undetectable in 6 patients, 4 in group 2 and 2 in group 3 (Table 2). The peripheral CD4+TL count correlated negatively with peripheral viral burden, reported as $\log$ values, with $\mathrm{r}=-0.365$ and $\mathrm{P}=$ 0.02 .

Only 2 patients in group $2(5.3 \%)$ were 
not on antiretroviral therapy because of normal peripheral CD4+TL count and low levels of viral burden. All patients in group 2 who were on antiretroviral therapy were using two NRTI and 33.3, 37.5, and $29.2 \%$ of group 3 patients were using 2 NRTI, 2 NRTI + saquinavir, and 2 NRTI + ritonavir/indinavir, respectively.

\section{Intestinal absorption, nutritional status and endoscopy}

None of the HIV+ patients presented alterations in the D-xylose test and none had loss of body weight or a body weight below the predicted value, based on height. Albumin, ferritin and magnesium levels did not differ between HIV+ patients and control subjects (data not shown).

Endoscopy was normal in all subjects in group 1. In group 2 and group 3 , bulbitis and/or duodenitis were present in 21.4 and $41.6 \%$ of the patients, respectively.

\section{Histopathological analyses}

Histology. Only HIV+ patients showed moderate or intense inflammation of the duodenal mucosa. A mild inflammatory infiltrate was significantly more prevalent among $\mathrm{HIV}+$ patients from group $3(\mathrm{P}=$ 0.01). A moderate or intense eosinophil infiltrate was also more prevalent among these patients $(\mathrm{P}=0.005)$ and also in patients in group $2(\mathrm{P}=0.05$; Table 3$)$. There was no significant difference between HIV+ patients and controls regarding villus to crypt ratio or number of mitoses (data not shown).

Cell populations. A significant reduction in mucosal CD4+TL was found in asymptomatic HIV+ patients compared to control. An even greater reduction was found among advanced disease subjects but no significant difference could be detected between the two groups of HIV+ patients (Figure 1, Table 4). There was no correlation between peripheral and mucosal CD4+TL when only data from $\mathrm{HIV}+$ patients were analyzed $(\mathrm{P}=$ 0.1 ; Figure 2).

To evaluate the mucosal and peripheral reduction rate of this cell population, the percentage of CD4+TL in relation to total lymphocyte numbers (CD3+ cells in the peripheral population and $\mathrm{CD} 45 \mathrm{RO}+$ cells in the duodenal mucosa) was determined. The proportional difference between the two populations was determined by the following formula: blood \% minus mucosal \% divided by blood \%. The values for each

Table 2. CD4+ T lymphocyte (TL), CD8+TL and CD3+TL counts and HIV load in peripheral blood.

\begin{tabular}{lccc}
\hline Variable & Group 1 $(\mathrm{N}=22)$ & Group 2 $(\mathrm{N}=14)$ & Group 3 $(\mathrm{N}=24)$ \\
\hline CD4+TL $^{\mathrm{a}}$ & $795.0(608.0-1180.0)$ & $383.5(286.0-501.0)$ & $192.5(103.0-249.0)$ \\
CD8+TL $^{\mathrm{a}}$ & $431.5(329.0-590.0)$ & $595.0(402.0-623.0)$ & $755.0(540.5-960.5)$ \\
CD3+TL $^{\mathrm{a}}$ & $1338.5(1014.0-1883.0)$ & $1016.5(838.0-1178.0)$ & $975.0(787.5-1227.0)$ \\
Viral load & - & $900.0(200.0-2050.0)$ & $10,065.0(3055.0-68,800.0)$ \\
Viral loadc & - & $2.94(2.3-3.31)$ & $4.0(3.48-4.78)$ \\
\hline
\end{tabular}

aMedian number of cells $/ \mathrm{mm}^{3}$ (lower-upper quartile). bMedian number of copies $/ \mathrm{mL}$ (lower-upper quartile). cMedian log (lower-upper quartile). For group definitions, see legend to Table 1.

CD4+TL: Kruskal-Wallis: $\mathrm{P}<0.0001$. Dunn: group 1 vs group 2: $\mathrm{Cl}=3.93-29.35$; group 1 vs group $3: \mathrm{Cl}=$ 23.42-45.36; group 2 vs group 3: $\mathrm{Cl}=5.25-30.25$.

CD8+TL: Kruskal-Wallis: $\mathrm{P}=0.007$. Dunn: group 1 vs group 2: $\mathrm{Cl}=-4.26-21.16$; group 1 vs group 3: $\mathrm{Cl}=5.23-$ 27.17; group 2 vs group 3: $\mathrm{Cl}=-4.75-20.25$.

CD3+TL: Kruskal-Wallis: $\mathrm{P}=0.03$. Dunn: group 1 vs group 2: $\mathrm{Cl}=-1.6-23.8$; group 1 vs group 3: $\mathrm{Cl}=1.6-23.5$; group 2 vs group $3: \mathrm{Cl}=-11.1-13.9$.

Viral load (log): Mann-Whitney: $\mathrm{P}<0.002$. 
Figure 1. Comparison of mucosal CD4+ T lymphocyte (CD4+TL) count between groups. KruskalWallis: $\mathrm{P}<0.00001$; Dunn: group 1 vs group 2: $\mathrm{Cl}=3.99$ 29.41; group 1 vs group $3: \mathrm{Cl}=$ 16.22-38.16; group 2 vs group 3 : $\mathrm{Cl}=-2.01-22.99$. For group definitions, see legend to Table 1. The boxplots show the minimum/ maximum value, 1 st and $3 \mathrm{rd}$ quartiles and median. *Possible outlier.



Table 3. Histopathological characteristics of the duodenal mucosa.

\begin{tabular}{lccc}
\hline Variable & $\begin{array}{c}\text { Group 1 } \\
(\mathrm{N}=22)\end{array}$ & $\begin{array}{c}\text { Group 2 } \\
(\mathrm{N}=14)\end{array}$ & $\begin{array}{c}\text { Group 3 } \\
(\mathrm{N}=24)\end{array}$ \\
\hline $\begin{array}{l}\text { Inflammatory infiltrate } \\
\text { (none/mild/moderate or intense) }\end{array}$ & $63.6 / 36.4 / 0.0$ & $21.4 / 64.3 / 14.3$ & $16.7 / 70.8 / 12.5$ \\
$\begin{array}{c}\text { Eosinophilic infiltrate } \\
\text { (none/mild/moderate or intense) }\end{array}$ & $54.5 / 45.5 / 0.0$ & $0.0 / 78.6 / 21.4$ & $20.8 / 4.2 / 25.0$ \\
$\begin{array}{c}\text { Lymphocyte density } \\
\text { (normal/increased/decreased) }\end{array}$ & $86.4 / 4.5 / 9.1$ & $35.7 / 7.1 / 57.1$ & $70.8 / 4.2 / 25.0$ \\
\hline
\end{tabular}

Data are reported as percentages. For group definitions, see legend to Table 1. Inflammatory infiltrate: $\chi^{2}: P=0.008$. Wald - mild: group 1 vs group $2: P=0.08$; group 1 vs group 3: $\mathrm{P}=0.01$; group 2 vs group 3: $\mathrm{P}=0.6$; moderate/intense: group 1 vs group 2: $\mathrm{P}=0.12$; group 1 vs group $3: \mathrm{P}=0.06$; group 2 vs group $3: \mathrm{P}=0.87$.

Eosinophilic infiltrate: $\chi^{2}: P=0.002$. Wald - mild: group 1 vs group $2: P=0.03$; group 1 vs group 3: $\mathrm{P}=0.55$; group 2 vs group 3: $\mathrm{P}=0.10$; moderate/intense: group 1 vs group $2: \mathrm{P}=0.05$; group 1 vs group $3: \mathrm{P}=0.005$; group 2 vs group $3: \mathrm{P}=0.79$.

Lymphocyte density: $\chi^{2}: P=0.03$. Wald - decreased: group 1 vs group 2: $P=0.001$; group 1 vs group 3: $\mathrm{P}=0.13$; group 2 vs group $3: \mathrm{P}=0.04$.

Table 4. Characteristics of the cell populations in the duodenal mucosa.

\begin{tabular}{lccc}
\hline Variable & $\begin{array}{c}\text { Group 1 } \\
(\mathrm{N}=22)\end{array}$ & $\begin{array}{l}\text { Group 2 } \\
(\mathrm{N}=14)\end{array}$ & $\begin{array}{c}\text { Group 3 } \\
(\mathrm{N}=24)\end{array}$ \\
\hline $\mathrm{CD} 4+\mathrm{TL}$ & $12.82(830-20.33)$ & $6.36(1.75-11.66)$ & $1.75(0.87-3.14)$ \\
$\mathrm{CD} 8+\mathrm{TL}$ & $9.35(2.40-13.60)$ & $5.41(2.20-9.28)$ & $6.93(1.30-18.00)$ \\
$\mathrm{CD} 45 \mathrm{RO}+\mathrm{TL}$ & $56.25(41.60-80.20)$ & $50.20(31.45-63.80)$ & $52.97(35.20-65.60)$ \\
$\mathrm{S} 100+$ cells & $3.07(2.00-4.67)$ & $1.80(0.60-4.28)$ & $1.43(0.28-3.55)$ \\
CD68+ cells & $2.24(1.00-4.62)$ & $1.80(0.50-3.20)$ & $1.80(0.60-4.50)$ \\
\hline
\end{tabular}

Data are reported as median number of cells $/ \mathrm{cm}^{2}$ in a high power field (lower-upper quartile). For group definitions, see legend to Table 1.

CD4+TL: Kruskal-Wallis: $\mathrm{P}=0.00001$. Dunn: group 1 vs 2: $\mathrm{Cl}=3.99-29.41$; group 1 vs group 3: $\mathrm{Cl}=16.22-38.16$; group 2 vs group 3: $\mathrm{Cl}=-2.01-22.99$.

CD8+TL: Kruskal-Wallis: $P=0.50$. Mann-Whitney: group 1 vs groups $2+3: P=0.54$. CD45RO+TL: Kruskal-Wallis: $P=0.31$. Mann-Whitney: group 1 vs groups $2+3: P=0.12$. S100+ cells: Kruskal-Wallis: $P=0.22$. Mann-Whitney: group 1 vs groups $2+3: P=0.10$. CD68+ cells: Kruskal-Wallis: $P=0.79$. Mann-Whitney: group 1 vs groups $2+3: P=0.56$. patient were analyzed by group. The median value was $0.637(0.474-0.685)$ for group 1 , $0.822(0.392-0.968)$ for group 2 , and 0.730 (0.357-0.821) for group 3, with no statistical difference among them $(\mathrm{P}=0.58)$, suggesting that the rate of mucosal and peripheral cell reduction was the same in both compartments.

There was no difference among groups regarding mucosal $\mathrm{CD} 8+\mathrm{TL}, \mathrm{CD} 45 \mathrm{RO}+\mathrm{TL}$ or CD68+ and S100+ cells (Table 4).

Cytokine patterns. There was no difference in the qualitative presence of cytokines among groups when asymptomatic and advanced disease patients were analyzed separately or when HIV+ patients were analyzed as a whole. Furthermore, no difference was found in the quantitative analysis of TNF- $\alpha$ or in the semi-quantitative analysis of TNF$\alpha$, IL- $1 \alpha$, IL-1ß, and IFN- $\gamma$. These results are listed in Table 5.

When the positivity for groups of cytokines, i.e., any of the pro-inflammatory cytokines (TNF- $\alpha$, IL-1 $\alpha$, or IL-1ß), any TH1 cytokine (IFN- $\gamma$ or CD25+, IL-2 receptor) and any TH2 cytokine (IL-4, IL-5, or IL-7) was analyzed, no difference was observed between groups $(\mathrm{P}=0.11,0.58$, and 0.48 , respectively, data not shown). Regarding this grouped analysis of cytokines, there was no correlation between any specific pattern and cell population $(\mathrm{CD} 4+\mathrm{L}, \mathrm{CD} 8+\mathrm{L}$, $\mathrm{CD} 45 \mathrm{RO}+\mathrm{L}$, antigen-presenting cells, and macrophages), peripheral CD4+TL or mucosal p24 positivity (p24+, data not shown). Nor was a correlation detected between positivity to IL-4 or IL-5 and eosinophilic infiltrate (data not shown). However, a higher viral burden, 3.86 (3.18-4.73), was detected in patients with a positive TH1 pattern than in those without this pattern, 1.48 (0.0-3.67), $\mathrm{P}=0.02$.

Mucosal HIV. Only in 6 patients could p24 be demonstrated, 3 in group 2 and 3 in group 3. There was a significant correlation between the presence of p24 and IL-4, with all patients positive to $\mathrm{p} 24$ being also posi- 
tive to IL-4 (Figure 3, Table 6). No correlation was found between mucosal p24 and other cytokines, group of cytokines, peripheral viral load $(P=0.31)$, degree of inflammation $(\mathrm{P}=0.21)$, presence of eosinophilic infiltrate $(\mathrm{P}=0.60)$, peripheral and mucosal CD4+TL ( $\mathrm{P}=0.06$ and 0.08 , respectively), mucosal CD8+TL $(\mathrm{P}=0.13)$, antigen-presenting cells $(\mathrm{P}=0.65)$, or macrophages $(\mathrm{P}=$ 0.88 ; data not shown). However, mucosal CD45RO+TL were significantly higher among p24+ patients (p24+: 77.0 (61.0-79.8) and $\mathrm{p} 24$ - patients: $43.6(31.7-62.8), \mathrm{P}=0.03$; Figure 4).

\section{Discussion}

In this study, patients in different stages of HIV infection were evaluated. An attempt was made to study a homogeneous population using the 1993 CDC revised classification (24) and some exclusion criteria. However, the size of group 2 reflects the fact that it is difficult to include really asymptomatic patients in studies that require invasive procedures. There was no difference in age between groups, but a higher percentage of males was found among HIV+ patients owing to the epidemiological characteristics of the disease in Brazil. Although gender-related differences in immunological behavior have been reported in autoimmune disorders (27), this did not seem to influence our results. The peripheral CD4+TL count and viral load of this subset of patients reflect a population with a reasonably controlled viral infection, even in the advanced disease group. This is probably secondary to the use of combined antiretroviral therapy.

It has been shown that intestinal absorption is affected in the majority of HIV+ patients with AIDS and in some of the asymptomatic subjects $(4,28)$. In the present study, no alteration was found, regardless of the stage of infection. A possible reason might be that these patients have a better immunological status.

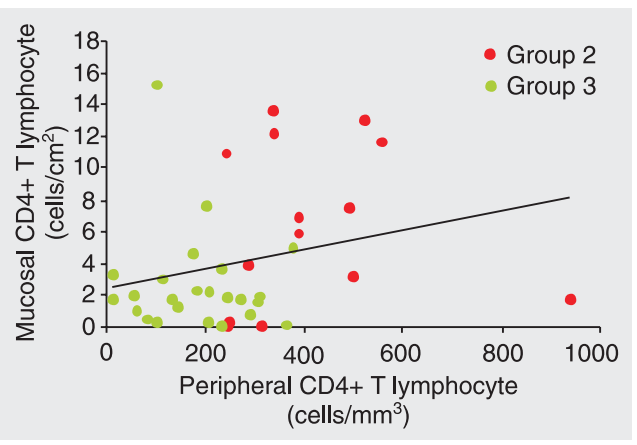

Figure 2. Correlation between mucosal and peripheral CD4+ T lymphocyte count, considering only $\mathrm{HIV}+$ patients (groups 2 (N $=14)$ and $3(N=24))$. Spearman: $r=0.26, P=0.1$. For group definitions, see legend to Table 1.

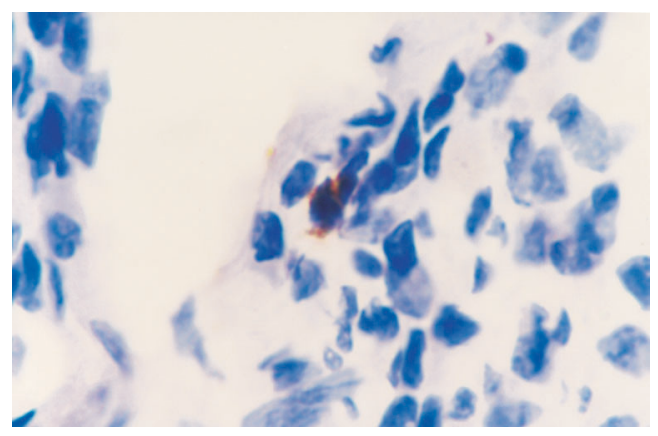

Figure 3. Immunohistochemical staining at $400 \mathrm{X}$ for IL-4 in the lamina propria of an HIV-positive patient from group 3. Positive cell is marked in orange.

Table 5. Characteristics of cytokines and IL-2 receptors in the duodenal mucosa.

\begin{tabular}{lccc}
\hline Variable & $\begin{array}{c}\text { Group 1 } \\
(\mathrm{N}=22)\end{array}$ & $\begin{array}{c}\text { Group 2 } \\
(\mathrm{N}=14)\end{array}$ & $\begin{array}{c}\text { Group 3 } \\
(\mathrm{N}=24)\end{array}$ \\
\hline TNF- $\alpha$ & $0.16(0.0-0.66)$ & $0.43(0.0-1.33)$ & $0.37(0.0-1.14)$ \\
TNF- $\alpha(-,+,++)$ & $42.9 / 38.1 / 19.0$ & $27.3 / 36.4 / 36.4$ & $26.1 / 47.8 / 26.4$ \\
IL-1 $\alpha(-,+,++)$ & $40.9 / 40.9 / 18.2$ & $38.5 / 30.8 / 30.8$ & $33.3 / 38.1 / 28.6$ \\
IL-1ß $(-,+,++)$ & $22.7 / 40.9 / 36.4$ & $16.7 / 33.3 / 50.0$ & $4.8 / 52.4 / 42.9$ \\
IFN- $\gamma(-,+,++)$ & $25.0 / 50.0 / 25.0$ & $16.7 / 58.3 / 25.0$ & $19.0 / 61.9 / 19.0$ \\
CD25+ (-, +) & $80.0 / 20.0$ & $53.8 / 46.2$ & $55.0 / 45.0$ \\
IL-4 $(-,+)$ & $52.9 / 47.1$ & $50.0 / 50.0$ & $42.9 / 57.1$ \\
IL-5 $(-,+)$ & $45.0 / 55.0$ & $36.4 / 63.6$ & $35.0 / 65.0$ \\
IL-7 $(-,++$ & $35.0 / 65.0$ & $63.6 / 36.4$ & $28.6 / 71.4$ \\
IL-8 $(-,+)$ & $60.0 / 40.0$ & $30.8 / 69.2$ & $52.4 / 47.6$ \\
TGF- $3(-,+)$ & $63.2 / 36.8$ & $61.5 / 38.5$ & $60.0 / 40.0$ \\
\end{tabular}

Data are reported in median (lower-upper quartile) number of positive cells in a high power field. All other results are reported as percentage. CD25+ which contains an IL2 receptor was used to evaluate this cytokine. For group definitions, see legend to Table 1.

TNF- $\alpha$ : Kruskal-Wallis: $\mathrm{P}=0.45 . \chi^{2}$ : group 1 vs group 2 vs group $3: \mathrm{P}=0.69$; group 1 vs groups $2+3: P=0.42$.

IL-1 $\alpha: \chi^{2}$ : group 1 vs group 2 vs group $3: \mathrm{P}=0.89$; group 1 vs groups $2+3: \mathrm{P}=0.63$. IL-1B: $\chi^{2}$ : group 1 vs group 2 vs group $3: \mathrm{P}=0.48$; group 1 vs groups $2+3: \mathrm{P}=0.36$. IFN- $\gamma$ : $\chi^{2}$ : group 1 vs group 2 vs group $3: \mathrm{P}=0.95$; group 1 vs groups $2+3: \mathrm{P}=0.76$. CD25+: $\chi^{2}$ : group 1 vs group 2 vs group 3: $\mathrm{P}=0.17$; group 1 vs groups $2+3: \mathrm{P}=0.06$. IL-4: $\chi^{2}$ : group 1 vs group 2 vs group $3: \mathrm{P}=0.81$; group 1 vs groups $2+3: \mathrm{P}=0.61$. IL-5: $\chi^{2}$ : group 1 vs group 2 vs group $3: \mathrm{P}=0.79$; group 1 vs groups $2+3: \mathrm{P}=0.50$. IL-7: $\chi^{2}$ : group 1 vs group 2 vs group $3: \mathrm{P}=0.14$; group 1 vs groups $2+3: \mathrm{P}=0.68$. IL-8: $\chi^{2}$ : group 1 vs group 2 vs group $3: \mathrm{P}=0.25$; group 1 vs groups $2+3: \mathrm{P}=0.26$. TGF- $ß$ : $\chi^{2}$ : group 1 vs group 2 vs group $3: \mathrm{P}=0.97$; group 1 vs groups $2+3: \mathrm{P}=0.85$. 
There was no significant difference regarding villus to crypt ratio or number of mitoses. Most studies in which mucosal atrophy was present were conducted on patients with advanced disease, with diarrhea and intestinal opportunistic infections $(4,5)$. These alterations were secondary to a local disruption of the immune system, consisting of modifications in the subpopulations of $\mathrm{T}$ cells and cytokines due to the presence of HIV or other infectious agents. In our population, patients were on antiretroviral therapy, with low viral load and reasonable CD4+TL counts. Moreover, none of the patients had opportunistic intestinal infections. These characteristics may explain this nearly normal mucosal pattern.

Qualitative analysis revealed the predominance of an eosinophilic inflammatory infiltrate in HIV+ patients. Many investigators have shown this, mostly in the advanced stage of the disease $(16,29)$. There are some possible reasons for this, with unidentified opportunistic infections or the presence of HIV itself being possibly responsible for the recruitment of eosinophils (29). In the pres-

Table 6. IL-4 positivity in duodenal mucosa of patients with and without mucosal p24.

\begin{tabular}{|c|c|c|c|c|c|c|}
\hline \multirow[t]{2}{*}{ Cytokine } & \multicolumn{2}{|c|}{ p24 negative } & \multicolumn{2}{|c|}{ p24 positive } & \multicolumn{2}{|c|}{ Total } \\
\hline & $N$ & $\%$ & N & $\%$ & $\mathrm{~N}$ & $\%$ \\
\hline IL-4 negative & 14 & 51.8 & 0 & 0.0 & 14 & 43.7 \\
\hline IL-4 positive & 13 & 48.2 & 5 & 100.0 & 18 & 56.3 \\
\hline Total & 27 & 100.0 & 5 & 100.0 & 32 & 100.0 \\
\hline
\end{tabular}

$\mathrm{N}=$ number of individuals. $\chi^{2}: \mathrm{P}=0.05$.

Figure 4. Comparison of mucosal CD45RO+ T lymphocyte (TL) count between mucosal p24-positive $(\mathrm{N}=6)$ and -negative patients $(\mathrm{N}=28)$. MannWhitney: $P=0.03$. Only individuals from groups 2 and 3 were analyzed. The boxplots show the minimum/maximum value, 1st and 3rd quartiles and median.

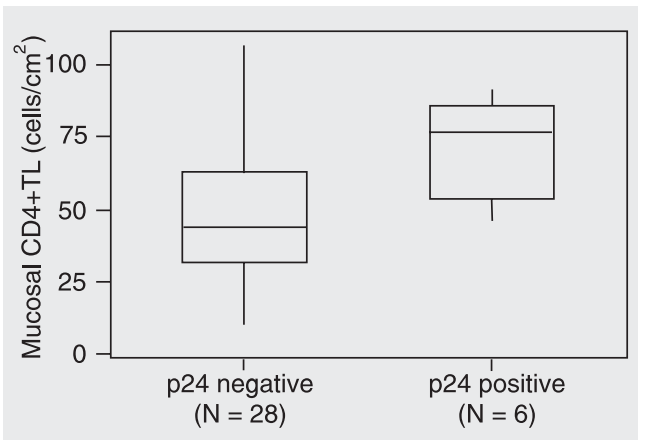

ent study, all patients with p24 positivity in the mucosa had a rich eosinophilic infiltrate. Another possible explanation is the presence of TH2 cytokines. Nevertheless, a TH2 response in asymptomatic patients seems improbable. Moreover, the TH2 cytokine positivity did not differ between HIV+ patients and controls. Other chemotactic factors such as eotaxin and immunoglobulin $\mathrm{E}$ could be responsible, but they were not assessed.

A significant reduction in the total intestinal mucosa CD4+TL was observed in HIV+ patients, confirming previous studies $(11,12$, 30-32). This reduction did not correlate with disease stage, probably because of the small number of patients in group 2. A reduction in mucosal CD4+TL count in asymptomatic patients has been reported $(11,12)$. These investigators, however, included in the analysis patients that could not be considered to be in the early phases of the infection, since many of them had diseases such as esophageal ulcers, oral candidiasis and even low peripheral CD4+TL counts. This may have contributed to an overall reduction in mucosal cells. In the present study, the reduction was clearly demonstrated in asymptomatic individuals. CD4+ cells can be either macrophages or lymphocytes. It has been suggested that these CD4+ cells are really lymphocytes since the total number of CD68+ cells is unchanged. This is in agreement with a recent publication whose authors showed that lamina propria lymphocytes and not macrophages are the preferential target for HIV replication in the early stages of infection (33).

The correlation between peripheral and mucosa CD4+TL counts was not clear. Nevertheless, the percentage of CD4+TL reduction was the same in the blood and the mucosa in either asymptomatic or advanced disease patients, showing a similar pattern of derangement. A more pronounced reduction of CD4+TL in the mucosa, as shown in another study (12), might be secondary to a 
permanent activation status of the mucosal lymphocytes. This activation turns them into a preferential target for HIV replication, with consequent higher destruction of CD4+TL (12). It has been recently shown that mucosal mononuclear cells are more easily infected with HIV than peripheral cells, a fact that contributes to their destruction $(34,35)$. In the absence of opportunistic infections, as in the present study, the activation status tends to be lower, with a lower destruction of mucosal CD4+TL. Therefore, the rate of destruction would be the same as in peripheral blood.

The characteristic pattern of an increased CD8+TL count, already demonstrated in the mucosa (36), was observed only in the peripheral blood of advanced disease patients. Our patients had a low positivity for p24 antigen in the mucosa, in addition to the absence of opportunistic infections in the intestine. It is possible that these factors contributed to the absence of a cytotoxic response.

Regarding the change in cytokine profile, a switch from a $\mathrm{TH} 1$ to a $\mathrm{TH} 2$ pattern was not observed during the progression of the disease. Nevertheless, many published papers have shown differences, although with conflicting results $(15-18,36,37)$. Some investigators state that during the progression of the disease there is a continuous loss of TH1 function, with the predominance of the $\mathrm{TH} 2$ response in an intermediate phase. In an advanced phase, an extreme immunological derangement may take place, with the predominance of pro-inflammatory cytokines. This pattern may be secondary to the presence of opportunistic infections (16, 17). This was not confirmed in the present study.

Most of the previous studies included patients with opportunistic infections, either on monotherapy or on non-reported medications. Moreover, the viral load was not determined. These populations were very different from the present one, inasmuch as our patients had a low viral load and no opportunistic infection and many were under combined antiretroviral therapy, that is to say, a low stimulus to cytokine production. The maintenance of this pattern could also be secondary to a higher synthesis of such cytokines by residual CD4+TL, at least in the early phases of the infection (38). Moreover, the other cell populations were preserved in our patients and may have contributed to a basal level of cytokine production. It has been suggested that CD8+TL may be capable of producing IFN- $\gamma(31)$. Also natural killer cells and macrophages are able to produce IL-1 and IFN- $\gamma$ (15). It is possible that a nearly normal immune stage, regarding cytokines, could be maintained regardless of CD4+TL depletion. The continuous loss of these cells in the advanced stages of infection, however, would lead to a failure of this compensation mechanism since the activation of these other cells depends on the direct stimulus from CD4+TL.

In the present study, the presence of HIV in the mucosa was evaluated on the basis of the positivity for p24 antigen. However, this positivity does not clearly indicate that HIV is infecting other cells, nor can it be used to quantify the degree of infection (39). The sensitivity of p24 antigen to detect the presence of HIV is lower than that of other techniques (39). Nevertheless, our low prevalence does not seem to be related to the sensitivity of the assay. Using the same methodology, other investigators have found HIV proteins in $30-56 \%$ of the patients in different stages of the infection $(1,10,29)$ and even in $100 \%$ of patients not receiving antiretroviral therapy (13). This lower prevalence might be related to the use of combined antiretroviral therapy. Some investigators were not able to show a difference in the amount of mucosal HIV in patients on antiretroviral therapy. However, in most cases the patients were on monotherapy with AZT (16) or on double therapy with two reverse transcriptase inhibitors $(16,40)$. This type of 
therapy is less efficient in reducing viral load. The absence of opportunistic infections, reducing the degree of activation in mucosal cells and therefore viral replication, might have also contributed.

This low prevalence of HIV in mucosa, however, hampers an analysis of the possible correlations between mucosal HIV and cellular populations or cytokine pattern. Even so, we were able to demonstrate a significant increase in IL-4 secretion in mucosal p24positive patients. As already mentioned, the influence of opportunistic agents is improbable. This increase could be an indirect sign of a $\mathrm{TH} 2$ predominance in advanced stages of infection, when the presence of HIV in the mucosa may be more intense. This suggests that the absence of a correlation between cytokine pattern and HIV infection might be related to a low viral load secondary to HAART. In other words, if our patients had more pronounced infection in the mucosa, it would be easier to detect a predominance of the TH2 pattern. A higher number of mucosal CD45RO+L in $\mathrm{p} 24+$ patients has been reported (40) and might be secondary to the proliferative stimulation of the virus.

The duodenal mucosa of these HIV+ patients seems to be nearly normal regarding histological alterations. This pattern may be characteristic of a population without opportunistic infections and taking potent antiretroviral therapy, with a better preservation of the immune status. It seems that during antiretroviral therapy a significant reduction in mucosal viral load occurs, with a conse- quent preservation of the mucosal architecture, cellular populations and cytokine patterns. The low levels of p24 antigen in the mucosa might suggest that antiretroviral therapy was efficient in controlling viral infection and its consequences. We also suggest that the impact of HIV infection in this population is higher in peripheral blood than in the mucosa, where there is a better preservation of the T lymphocyte subpopulations, macrophages and antigen-presenting cells. These cells would be responsible for the preservation of the cytokine pattern.

The discrepancy between this and previous studies might be explained by the characteristics of the population, by the criteria used to define different phases of the infection as well as differences in methodology, including the criteria used to count cells. Nonetheless, our understanding of all physiopathological mechanisms of cytokine production and all the interactions between mucosal inflammatory cells is far from complete.

In conclusion, antiretroviral therapy seems to have an impact in the preservation of the duodenal mucosa of HIV+ patients, probably because there is a better preservation of the immune status, with low local viral load and absence of opportunistic infections.

\section{Acknowledgments}

We thank Mariana Cury for statistical analysis.

\section{References}

1. Ehrenpreis ED, Patterson BK, Brainer JA et al. (1992). Histopathologic findings of duodenal biopsy specimens in HIV-infected patients with and without diarrhea and malabsorption. American Journal of Clinical Pathology, 97: 21-28.

2. Bjarnason I, Sharpstone DR, Francis N et al. (1996). Intestinal inflammation, ileal structure and function in HIV. AIDS, 10: 13851391.

3. Oktedalen O, Skar V, Dahl E et al. (1998). Changes in small intesti- nal structure and function in HIV-infected patients with chronic diarrhoea. Scandinavian Journal of Infectious Diseases, 30: 459-463.

4. Kotler DP, Francisco A, Clayton F et al. (1990). Small intestine injury and parasitic diseases in AIDS. Annals of Internal Medicine, 113: 444-449.

5. Madi K, Trajman A, da Silva CF et al. (1991). Jejunal biopsy in HIVinfected patients. Journal of Acquired Immune Deficiency Syndrome, 4: 930-937. 
6. Bland PW (1998). Mucosal T cell-epithelial cell interactions. Chemical Immunology, 71: 40-63.

7. Podolsky DK (1999). Mucosal immunity and inflammation V. Innate mechanisms of mucosal defense and repair: the best offense is a good defense. American Journal of Physiology, 277: G495-G499.

8. Smith PD, Meng G, Salazar-Gonzalez JF et al. (2003). Macrophage HIV-1 infection and the gastrointestinal reservoir. Journal of Leukocyte Biology, 74: 642-649.

9. Anton PA, Mitsuyasu RT, Deeks SG et al. (2003). Multiple measures of HIV burden in blood and tissue are correlated with each other but not with clinical parameters in aviremic subjects. AIDS, 17: 53-63.

10. Jarry A, Cortez A, Rene E et al. (1990). Infected cells and immune cells in the gastrointestinal tract of AIDS patients. An immunohistochemical study of 127 cases. Histopathology, 16: 133-140.

11. Lim SG, Condez A, Lee CA et al. (1993). Loss of mucosal CD4 lymphocytes is an early feature of HIV infection. Clinical and Experimental Immunology, 92: 448-454.

12. Schneider T, Jahn HU, Schmidt $W$ et al. (1995). Loss of CD4 T lymphocytes in patients infected with human immunodeficiency virus type 1 is more pronounced in the duodenal mucosa than in the peripheral blood. Gut, 37: 524-529.

13. Carol M, Lambrechts A, Urbain D et al. (1998). Persistent T cell and $B$ cell activities in the duodenal mucosa of AIDS patients. AIDS, 12: 1763-1769.

14. MacDonald TT (1999). Effector and regulatory lymphoid cells and cytokines in mucosal sites. Current Topics in Microbiology and Immunology, 236: 113-137.

15. McGowan I, Radford-Smith G \& Jewell DP (1994). Cytokine gene expression in HIV-infected intestinal mucosa. AIDS, 8: 1569-1575.

16. Kotler DP, Reka S \& Clayton F (1993). Intestinal mucosal inflammation associated with human immunodeficiency virus infection. Digestive Diseases and Sciences, 38: 1119-1127.

17. Reka S, Garro ML \& Kotler DP (1994). Variation in the expression of human immunodeficiency virus RNA and cytokine mRNA in rectal mucosa during the progression of infection. Lymphokine and $\mathrm{Cy}$ tokine Research, 13: 391-398.

18. Steffen M, Reinecker HC, Petersen J et al. (1993). Differences in cytokine secretion by intestinal mononuclear cells, peripheral blood monocytes and alveolar macrophages from HIV-infected patients. Clinical and Experimental Immunology, 91: 30-36.

19. Snijders F, van Deventer SJ, Bartelsman JF et al. (1995). Diarrhoea in HIV-infected patients: no evidence of cytokine-mediated inflammation in jejunal mucosa. AIDS, 9: 367-373.

20. Kotler DP, Shimada T, Snow G et al. (1998). Effect of combination antiretroviral therapy upon rectal mucosal HIV RNA burden and mononuclear cell apoptosis. AIDS, 12: 597-604.

21. Monkemuller KE, Call SA, Lazenby AJ et al. (2000). Declining prevalence of opportunistic gastrointestinal disease in the era of combination therapy. American Journal of Gastroenterology, 95: 457-462.

22. Jannof E \& Smith PD (2001). Emerging concepts in gastrointestinal aspects of HIV-1 pathogenesis and management. Gastroenterology, 120: 607-621.

23. Schmidt W, Wahnschaffe U, Schafer M et al. (2001). Rapid increase of mucosal CD4T cells followed by clearance of intestinal cryptosporidiosis in an AIDS patient receiving highly active antiretroviral therapy. Gastroenterology, 120: 984-987.

24. Centers for Diseases Control (1992). 1993-Revised Classification System for HIV infection and expanded surveillance case definition for AIDS among adolescents and adults. Morbidity and Mortality Weekly Report. Recommendations and Reports, 41: 1-19.
25. Hsu SM, Raine L \& Fanger H (1981). Use of avidin-biotin-peroxidase complex $(A B C)$ in immunoperoxidase techniques: a comparison between $A B C$ and unlabeled antibody (PAP) procedure. Journal of Histochemistry and Cytochemistry, 29: 577-580.

26. Bobrow MN, Harris TD, Shaughnessy KJ et al. (1989). Catalyzed reporter deposition, a novel method of signal amplification. Application to immunoassays. Journal of Immunological Methods, 125: 279-285.

27. Silva JAP (1999). Sex hormones and glucocorticoids: interactions with the immune system. Annals of the New York Academy of Sciences, 876: 102-118.

28. Machado FR, Gonzaga Vaz Coelho L, Chausson Y et al. (2000). Fat malabsorption assessed by ${ }^{14} \mathrm{C}$-triolein breath test in HIV positive patients in different stages of infection: is it an early event? Journal of Clinical Gastroenterology, 30: 403-408.

29. Clayton F, Reka S, Cronin WJ et al. (1992). Rectal mucosal pathology varies with human immunodeficiency virus antigen content and disease stage. Gastroenterology, 103: 919-933.

30. Snijders F, Meenan J, van den Blink B et al. (1996). Duodenal intraepithelial and lamina propria $T$ lymphocytes in human immunodeficiency virus-infected patients with and without diarhoea. Scandinavian Journal of Gastroenterology, 31: 1176-1181.

31. Carol M, Lambrechts A, Van Gossum A et al. (1998). Spontaneous secretion of interferon $\gamma$ and interleukin 4 by human intraepithelial and lamina propria gut lymphocytes. Gut, 42: 643-649.

32. Schneider T, Ullrich R, Bergs C et al. (1994). Abnormalities in subset distribution, activation and differentiation of $T$ cells isolated from large intestine biopsies in HIV infection. Clinical and Experimental Immunology, 95: 430-435.

33. Meng G, Sellers MT, Mosteller-Barnum M et al. (2000). Lamina propria lymphocytes, not macrophages, express CCR5 and CXCR4 and are the likely target cell for human immunodeficiency virus type 1 in the intestinal mucosa. Journal of Infectious Diseases, 182: 785791.

34. Anton PA, Elliott J, Poles MA et al. (2000). Enhanced levels of functional HIV-1 co-receptors on human mucosal T cells demonstrated using intestinal biopsy tissue. AIDS, 14: 1761-1765.

35. Lapenta C, Boirivant M, Marini M et al. (1999). Human intestinal lamina propria lymphocytes are naturally permissive to HIV-1 infection. European Journal of Immunology, 29: 1202-1208.

36. Olsson J, Poles M, Spetz AL et al. (2000). Human immunodeficiency virus type 1 infection is associated with significant mucosal inflammation characterized by increased expression of CCR5, CXCR4 and B-chemokines. Journal of Infectious Diseases, 182: 1625-1635.

37. Sharpstone DR, Rowbottom AW, Nelson MR et al. (1996). Faecal tumour necrosis factor- $\alpha$ in individuals with HIV-related diarrhoea. AIDS, 10: 989-994.

38. Smit-McBride Z, Mattapallil JJ, McChesney M et al. (1998). Gastrointestinal $\mathrm{T}$ lymphocytes retain high potential for cytokine responses but have severe CD4+ T-cell depletion at all stages of simian immunodeficiency virus infection compared to peripheral lymphocytes. Journal of Virology, 72: 6646-6656.

39. Kotler DP, Reka S, Borcich A et al. (1991). Detection, localization and quantitation of HIV-associated antigens in intestinal biopsies from patients with HIV. American Journal of Pathology, 139: 823830.

40. Fackler OT, Schafer M, Schmidt W et al. (1998). HIV-1 p24 but not proviral load is increased in the intestinal mucosa compared with the peripheral blood in HIV-infected patients. AIDS, 12: 139-146. 